$$
\text { "plaza" — 2007/2/16 — 14:14 — page } 451 \text { — \#1 }
$$

\title{
Proof without words: Knopp series for $\pi$
}

\author{
Ángel Plaza
}

There are many expressions for number $\pi$ as infinite series or infinite product (see for example $[1,2,3]$ ). In [1] the following series for number $\pi$ is attributed to K. Knopp:

$$
\frac{\pi}{4}=\sum_{k=1}^{\infty} \arctan \left(\frac{1}{k^{2}+k+1}\right)
$$

Note that in this formula, transcendent number $\pi$ is represented as the infinite sum of transcendent numbers. However a simple visual proof is provided here.

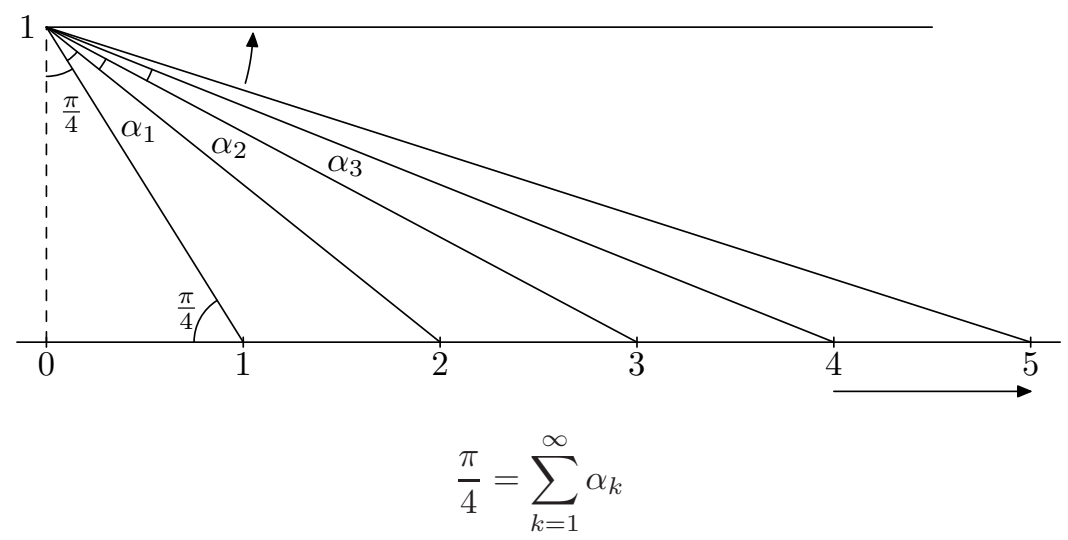

Copyright (c) 2006 by University of Debrecen 


$$
\text { "plaza" — 2007/2/16 — 14:14 — page } 452 \text { — \#2 }
$$

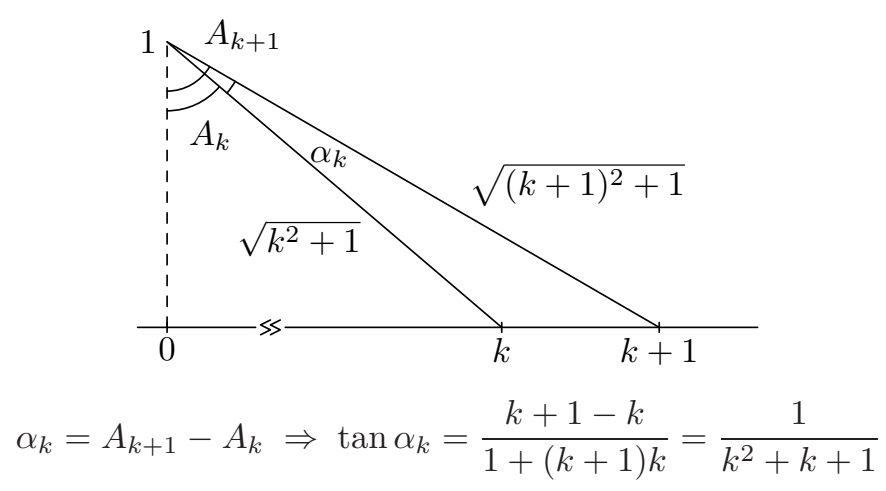

\section{References}

[1] X. Gourdon, P. Sebah, Collection of Series for $\pi$, http://numbers . computation.free.fr/Constants/Pi/piSeries.html.

[2] K. Knopp, Theory and Application of Infinite Series, Dover, New York, 1990, $214-215$.

[3] E. W. Weisstein, Pi Formulas, MathWorld - A Wolfram Web Resource, http://mathworld.wolfram.com/PiFormulas.html.

ÁNGEL PLAZA

DEPARTMENT OF MATHEMATICS

UNIVERSITY OF LAS PALMAS DE GRAN CANARIA

EDIFICIO DE INFORMÁTICA Y MATEMÁTICAS

35017-LAS PALMAS DE GRAN CANARIA

SPAIN

E-mail: aplaza@dmat.ulpgc.es

(Received July, 2006) 